\title{
Predictors in Complicated Grief: Supporting Families in Palliative Care Dealing with Grief
}

\author{
Pilar Barreto-Martín, Marián Pérez-Marín and Patricia Yi \\ University of Valencia, \\ Department of Personality, \\ Assessment and psychological Treatment, \\ Spain
}

\section{Introduction}

The construction of a person's identity is an evolutionary process. Living implies passing through a series of bereavements and this development gives time to the ego for the management of loss. It also permits recovery from the transitory moments of alteration of identity (Grinberg, 1980). As it has been thoroughly documented, in problematic cases, if the management of bereavement fails, serious disturbances in bereavement or pathological formations happen (Gamo \& Pazos, 2009).

As it is known, bereavement is the natural result of the loss of any person, thing or value, one has developed an affective link with. As such, it is a natural and human process and not an illness which must be avoided or cured. The expression of bereavement includes reactions which very often appear similar to those which accompany physical, mental or emotional disorders (Payas, 2007).

Different researchers, even using different conceptual models, agree that bereavement is a complex and multidimensional process, influenced by physical, psychological, social and cultural elements (Barreto \& Soler, 2007; Corr \& Coolican, 2010; Meuser \& Marwit, 2001; Kissane, Block \& Mckenzie, 1997; Stroebe, Hansson, Schut, \& Stroebe, 2008). Thus, research in bereavement has increased in recent years around the world and many efforts toward consensus have been made (Stroebe et al., 2008).

Early studies were systematic reviews of a conceptual nature, symptoms and types of grief (normal versus complicated, chronic, prolonged, delayed, inhibited, absent grief) and their effects on health.

From a conceptual viewpoint, bereavement is the term used to denote the objective situation of having lost a significant one through death. Grief is the term applied to the primarily emotional (affective) reaction to the loss of a loved one through death. Mourning is related to the public display of grief, the social expression or expressive acts of grief that are connected to the beliefs (often religious) and practices of a given society or cultural group (Stroebe et al, 2008).

Moreover, grief is a process of affliction, sorrow, regret and/or pain, challenging the person actively. The emotional experience of dealing with loss is called the grief process and it 
refers to the need to adapt to a new situation. We also know that bereavement is a common, painful and universal human experience (Bayes, 2001; Bayes, 2006; Corr \& Coolican, 2010). We all suffer loss and we feel the anguish that it is involved with it.

Full of basic notions, bereavement is simultaneously universal and individual, benign and malignant. It is helpful and harmful, active and passive, internal and external, a state and a process (Moules, Simonson, Fleiser, Prins \& Glasgow, 2007). Bereavement is universal in the sense that it is an unavoidable aspect of life because we are finite beings. It is individual because people develop their own, intimate, personal and unique bereavement. Bereaved persons may development a substantial change in their vision of the world. It can lead to personal growth, and in that sense it is benign and helpful. But it also implies the danger of regressing or becoming paralyzed and in that aspect it is malignant and harmful. Worden is one of the authors who most insist on the active role of the person in the development of bereavement (Worden, 1991/1997). Finally, bereavement is a dynamic process which evolves over time although in the emotionally painful moment the sufferer has the impression that the world is paralyzed.

In the specialized literature we can find a large number of attempts to define it, which illustrates its multidimensionality and its primarily active and adaptive role (Bonnano et al, 1999; Altet \&Boatas 2000; Gamo, Del Alamo, \& Hernangómez, 2000, Gamo \& Pazos, 2009; SECPAL 2002; Barreto \& Soler, 2007)

The American Psychiatric Association has also tried to delineate the concept of bereavement. Thus, in the Diagnostic and Statistical Manual of Mental Disorders (APA, 2003) bereavement figures as a reaction to the death of a loved one, an entity which may need clinical attention and which may have symptoms similar to major depression, such as sadness, insomnia and anorexia.

Most of the people immersed in the process of bereavement will recover more or less in a relatively short period of time which usually ranges from two to three years (Limonero, 1996; Neimeyer, 2002; Worden, 1997; Amurrio \& Limonero, 1997). However a group of factors referred to by clinicians and investigators, can condition negatively or positively this process, increasing or ameliorating its intensity and duration and, therefore, the suffering (Bonnano \& Katlman,2001; Zhang et al, 2006). These aspects are related to the characteristics of the person who died (the affective significance of the loss), the relation maintained with the deceased, the characteristics of the family member, the circumstances of the death, the strategies of coping, social assistance and religion (Parkes, 1988; Herbert et al. 2009; Stroebe et al., 2001b; Sanders, 1999; Wortmann \& Part, 2008; Wortman et al., 1999). In the same way, different investigations have shown that mourners in general have a higher rate of morbidity and mortality (Stroebe et al, 2007; Zivin \& Christakis, 2007), and that more than $25 \%$ of outpatient care requests are related to psychological aspects which have their origin in the loss of a loved one (Bayes, 2006; McChrystal, 2008).

Thus, we need to keep in mind that for some mourners the process of bereavement can become complicated and extended in time (Limonero et al, 2009), bringing additional suffering. When risk factors have been detected in the mourners, it is necessary to offer them effective psychological and/or pharmacological treatment. And for them to accept it.

Given this scenario, good practice requires evaluating the existence of risk factors, the evolution of the manifestations during the process, the collection of family data which 
facilitate greater precision in the evaluation and the previous psychological alterations exhibited by family members in mourning (Kissane et al, 1997; Barreto et al, 2008; Chiu et al, 2010). All these factors give a personal profile which can detect individuals more prone to complications in the bereavement process and therefore in more need of specialized interventions (Barreto et al., 2008; Limonero et al., 2009; Soler \& Barreto, 2003; Kristjanson et al., 2005).

It is also important to point out how social changes imply variations in the community support individuals receive (Gil-Julia et al. 2008) and also, as Rando (1993) refers, in the increased prevalence of complicated bereavements in the current population. This author attributes this increase to some socio-cultural and technological changes prevalent today, which influence types of death, characteristics of personal relations, personality and the resources of mourners. These facts emphasize the relevance of the sociocultural context (Walter, 2000) and the malleability of bereavement as affected by sociocultural variables (Yi et al., 2006).

Currently, grief support to relatives of patients in palliative care is recognized as a fundamental practice within palliative medicine.

Working with the objective of improving psychological care for persons in bereavement, our research group has obtained interesting results in studying the following themes: determination of the degree of implantation of psychological services in palliative care units in Spain for persons in bereavement; the indicators of a complicated bereavement process; and the risk and protective factors which can perturb or facilitate an adaptive development of the bereavement process.

In this chapter, we try to synthesize the results of our research group with those reflected in the literature, all in the light of the authors' clinical experience. Thus, we will discuss the manifestations of grief, its evolution and we will review the existing knowledge about the factors (mainly risk) prior to the loss that may predict subsequent complications in the mourning of family caregivers of patients in palliative care.

\section{Manifestations of grief: An overview}

According to Bayés $(2001,2006)$, we can consider three components in the grieving process: (a) a universal reaction to loss, in the sense that it is a facet which appears in all cultures, although its manifestations may be very different. (b) suffering, which may be associated with active behaviors of discomfort and with passive depression-like behavior. (c) possible negative effects on the health of the person who is grieving.

Most people deal with loss without professional help, but some, a minority, risk suffering lasting effects on health and it is essential to know the indicators that warn us about the danger of complicated grief in order to prevent it (Lacasta \& Soler, 2004, Barreto \& Soler, 2007; Cunill et al., 2010).

Grief indicators include reactions that often are similar to those that are expressions of physical, mental or emotional disorders. It is important to be very careful in the interpretation of certain reactions of grief that may look like as pathological, when they could be natural and appropriate manifestations according to the particular circumstances of the loss (Gil-Julia et al. 2008). 
Grief manifestations include a variety of feelings, thoughts and physical and motor aspects. Among the most commonly described feelings are sadness, anger, anxiety, helplessness, shock, yearning, and emancipation. We see a great variety of these manifestations in cognitive, physical and motor areas (Gil-julia et al., 2008, Barreto \& Soler, 2007):

Studies show us how these manifestations can change with the passing of time and prevail more in certain moments of the grief process (Maciejewski et al., 2007).

The grieving process goes through different stages although there is a disagreement over what they are and their empirical validity. These stages are highly variable from person to person (Maciejewki et al., 2007). The first descriptions of the grieving process proposed the existence of successive, essentially static stages: disbelief and shock, yearning, angry protests, depressive mood (hopelessness) and recovery or acceptance (Kubler-Ross, 1969/1975/2000), Bowlby 1993, Parkes, 1970). Nowadays, rather than speaking of specific successive stages, it is beginning to be accepted that although the symptoms of grief come and go, there is a gradual movement towards adaptation as time goes by (Hansson and Stroebe, 2007)

An important empirical study of the grieving process (Maciejewski et al, 2007) has shown that these phases are actually found in the normal process. This study also revealed some aspects not previously considered, such as, for example, that acceptance is an indicator that shows up at the moment that we learn about the loved one's death but that its maximum expression occurs after 2 years. This seems to be the time when the person really emotionally accepts the death. On the other hand, the so-called adverse or negative indicators (denial/disbelief, yearning, anger/rage and depression) have their onset peak before 6 months after the death.

Uncomplicated bereavement involves reconciliation: "the process that occurs as the bereaved individual works to integrate the new reality of moving forward in life without the physical presence of the person who died". Reconciliation is achieved through specific tasks that take place during bereavement.

Authors such as Worden (1991/1997) consider it appropriated to speak of tasks in the grieving process, implying that the person is active and can do something. Phases imply certain passivity, something that the grieving person goes through. Thus, Worden includes four grieving tasks: (a) accept the reality of the loss, (b) work on the emotions and pain caused by the loss, (c) adapt to an environment in which the loved one is absent and (d) emotionally relocate the deceased person and more on.

Similarly, Parkes \& Weiss (1983) consider three necessary tasks: (a) intellectual recognition and explanation of the loss, (b) emotional acceptance of the loss and (c) assumption of a new identity.

It is difficult to determine the completion of bereavement. Some authors (Moules et al., 2007) think that it really never ends, but it is considered that the most critical process ends when the person is able to retrospectively remember the deceased with serene affection, and this period seems to last between one and two years.

Likewise, the manifestations of grief are modulated by variables such as gender, age, relationship to the deceased, the cycle of family life and the cultural background of the bereaved (Payas, 2008). The main areas to be assessed to understand and prevent the 
inadequate progression of mourning would be the following: family structure and functioning, the story of the death, individual and family needs, behavioral problems and requests for intervention.

\subsection{A general definition of the grief phenomenon}

Although it has been widely studied, there is still disagreement about the definition of grieving (Howarth, 2011).

The Diagnostic and Statistical Manual of Mental Disorders (DSM-IV-TR) (APA, 2003) includes bereavement as an additional problems which may need clinical attention and defines it as the reaction to the death of a loved one.

According to the DSM-IV-TR, a bereavement V-code can be used when the focus of treatment is a client's reaction to the death of a loved one. Use code V62.82, not attributable to mental disorder. For them, bereavement or grief is an entity able to receive clinical attention that may cause symptoms similar to major depression, posttraumatic stress, sadness, insomnia and anorexia, with a chronic evolution implying a great deal of suffering and considerable healthcare costs. The manual indicates that during the first two months the bereaved may present depressive symptoms characteristic of a major depressive episode. They may be considered normal if it does not last longer or there is no suspicious of the presence of pathological mourning. On the other hand, the loss of loved ones is among the major psychosocial problems related to primary support group and social environment, classified on axis IV of the multiaxial classification (Barreto et al., 2008; Prigerson \& Jacobs, 2001; Stroebe \& Schut, 2001; Hansson \& Stroebe, 2007; Tomarken et al., 2008).

The international classification of diseases ICD-10 Mental and Behavioural Disorders (OMSWHO, 1992), in factors that influence health status and contact with health services, in problems associated with the support group, including family circumstances, uses code Z63.4 for normal grief (disappearance or death of a family member), while uses code F43.2 adjustment disorders for grief reactions of any length which are considered abnormal because of their manifestations or content (Gil-Julia et al. 2008).

Since most people come to terms with the death of a loved one and regain their interest and engagement in ongoing life, as we commented earlier, clinicians should be cautious about suggesting that a bereaved person can expect to follow a predictable pathway (Shear \& Mulhare, 2008).

Adjustment occurs during a period of acute grief, when confrontation with the painful reality oscillates with defensive exclusion, in the form of numbing, focusing on positive memories, imagined reunion, and other forms of respire in which attention is directed toward neutral or positive thoughts (Shear \& Mulhare, 2008).

Acute Grief lasts most of the day, every day for up to 6 months. It is characterized by: a sense of disbelief; difficulty accepting the death; a mix of emotions with painful emotions usually dominant; thoughts and memories of the deceased are prominent and preoccupying; interest and engagement in ongoing life is attenuated and focused on bereavement-related activities (Shear \& Mulhare, 2008).

Integrated Grief is primarily a background state; grief occurs intermittently and changes over time. It is characterized by: comprehension of the death; thoughts and memories of the 
deceased accessible but not preoccupying; interest and engagement in life are re-established; a mix of emotions with positive emotions usually dominant (Shear \& Mulhare, 2008).

Its not easy to establish the differences between normal and pathological bereavement or grief (Altet \& Botas, 2000; Corr \& Coolican, 2010).

\subsection{Complicated grief: A brief history of the evolution of the concept}

Complicated grief has been defined as a deviation from the normal (in cultural and social terms) grief experience in either length of time, intensity, or both, entailing a chronic and more intense emotional experience or an inhibited response, which either lacks the usual symptoms or in which onset of symptoms is delayed (Stroebe et al., 2007).

Among the terms that have been used in the bereavement literature to describe atypical grief are: complicated grief (CG); traumatic bereavement; childhood traumatic grief; and, lastly, prolonged grief disorder (PGD) (Howarth, 2011).

Complicated grief interferes significantly in the overall functioning of people, compromising their health and as stated by Maddocks (2003), it may last for years or even become chronic (Barreto et al., 2008)

It is difficult to estimate the incidence of complicated grief in the general population. Different authors are interested in this problem and have observed that after the loss of a significant person, speaking of estimated averages, in the general population, two thirds of mourners evolve normally and the rest suffer alterations in their physical health, mental health or both (Olmeda, García Olmos \& Basurte, 2002). Jacobs (1999) for example, reports a percentage of 10 to $20 \%$ having problems in resolving their grief, Bonanno and Kaltman (2001) noted 10 to $15 \%$ of their samples, and Maercker et al (2005) found only $7.4 \%$ of people with complicated grief in a sample of older people. Different populations and clinical criteria may account for these discrepancies.

If we estimate that each deceased leaves an average of 5 mourners (Shear et al., 2005) and of these about $15 \%$ develop complicated grief, we will have about 300,000 people with complicated grief per year in the USA, for example.

Currently, there is no consensus diagnosis in part because complicated grief is not included in the classification of the DSM-IV-TR. However, certain symptoms that are not characteristic of "normal" bereavement and may be useful in differentiation from major depressive disorder have been included in additional problems that may need clinical care. The first is guilt for things, rather than actions, received or not received by the survivor at the time of death of the loved one. The second is thoughts of death rather than will to live with the feeling that the survivor should have died with the deceased. The third is morbid preoccupation with uselessness. The fourth is pronounced psychomotor slowing. The fifth is pronounced and prolonged functional impairment, and the sixth is hallucinatory experiences other than hearing the voice or see the fleeting image of the deceased.

As noted above, the line between normal grief and complicated grief can be very thin. The findings suggest that if not treated appropriately the condition may cause negative, longterm, mental health consequences. As a result, researchers are making attempts to define complicated grief, understand its relation to various adaptive responses and desired mental health outcomes, and identify efficacious interventions. 
Some researchers have proposed specific diagnostic criteria (Forstmaier \& Maercker, 2007; Horowitz, Siegel, Holen, Bonanno, Milbrath, \& Stinson, 1998; Prigerson and Jacobs, 2001; Prigerson et al, 2008; Stroebe et al, 2008b; Stroebe et al, 2008c; Shimshon et al, 2008; Frances, Pies \& Zisook, 2010).

Traditionally, a classification according to type of complication (anticipatory, chronic, delayed and repressive or avoidant grief) (Parkes, 1990) has been used, but there is currently an attempt to refine the boundaries using the indicators that allow for the diagnosis. The most used in research are those of the DSM -IV-TR (APA, 2003). Others have been operationalized in a questionnaire called the Inventory of Complicated Grief (ICG) established by a group of researchers led by Prigerson.

Both criteria set out different aspects of the phenomenon, the DSM includes mainly the possible psychopathology of mourning, while the ICG includes responses to grief, normal in principle, resulting from the processes of bonding and those that refer to coping with stress. It is also important to note that the DSM criteria is established and accepted in this field and the ICG is still under revision.

Fortunately, the group effort of Prigerson (Prigerson et al. 1999; Prigerson \& Jacobs, 2001) can reduce the lack of consensus. According to them, the syndrome or disorder of "traumatic grief" brings together distinct manifestations which can be grouped into two different categories referred to, on one hand, as separation distress (intrusive thoughts about the deceased, longing for the deceased, searching for the deceased despite knowing that he is dead and loneliness as a result of the death) and, on the other hand, the symptoms of traumatic distress (lack of goals and/or feelings of futility about the future, subjective feeling of indifference or lack of emotional response, difficulties in accepting the death, feeling that life is empty and/or meaningless, feeling that a part of oneself has died, feeling that the way of seeing and understanding the world has been shattered, take on symptoms and/or harmful behaviors of the deceased and excessive irritability, bitterness and/or anger in relation to the death). In summary, the diagnosis of complicated grief requires the death of a significant person, the simultaneous presence of several of the manifestations in each category with a certain intensity, frequency and duration and, finally, a serious deterioration in the social life, work or other significant activities of the bereaved.

These authors defend "traumatic grief" as a distinct entity from other syndromes listed in the DSM-IV-TR, such as major depressive disorder, adjustment disorder and posttraumatic stress disorder.

In addition to the listed events, clinical experience suggests other indicators of complicated grief: prolonged state of shock, antisocial behavior, escapes (running away), house-museum (full of mementos) or phobic avoidance (complete absence of them) (Soler \& Jordá, 1996).

Tracking studies tell of poor long-term prognosis. The percentage of people who develop complicated grief is relatively small but they may have physical or mental disorders for years and even decades.

Another interesting question under discussion concerns the time when complications in the process can be diagnosed, with the least possible error. DSM's proposal is that this moment should not be less than 6 months after the loss. However, Prigerson's group insists, following the results of its research and clinical experience, that complications detected at 6 months are already present 2 months after the loss (Prigerson \& Jacobs, 2001). 
Prior to the Prigerson's group, another system for the diagnosis of complicated grief had already been proposed by Horowitz et al. (1998). Independently, both groups proposed similar symptoms that tend specifically to characterize complicated grief (for example, yearning, disbelief, loneliness, emptiness, avoidance ...), suggesting a general agreement in principle on the symptoms of complicated grief. However, the study comparing the two systems' diagnoses of complicated grief, by Forstmeier \& Maercker (2007), found significant differences regarding prevalence and conditional probability, both being higher with the diagnostic system proposed by Horowitz's group. This same study also concludes that the set of criteria established by Horowitz's group is more inclusive and less strict than that of Prigerson's group and thus leads to a higher prevalence (Gil-Julia et al. 2008).

\subsection{Complicated grief: Differential diagnosis}

The Prigerson's group developed the first criteria for complicated grief. Later, these criteria were translated and adapted to Spanish (Garcia et al, 2002), which led to minor changes in them. Furthermore, these authors developed a diagnosis of complicated grief distinguishing it from other disorders listed in the DSM-IV-TR, such as posttraumatic stress disorder, major depressive disorder and adjustment disorder.

Shear \& Mulhare (2008) analyzed the similarities and differences between Complicated Grief (CG), Major Depression Disorder (MDD), and Posttraumatic stress disorder (PTSD):

- $\quad$ Similarities between MDD and Complicated Grief:

Sadness, loss of interest; Psychomotor retardation; Guilt; Sleep and appetite disturbances; Difficulty concentrating.

- Similarities between PTSD and Complicated Grief:

Triggered by a traumatic event; Sense of shock, helplessness; Intrusive images; Avoidance behaviour.

- $\quad$ Differences between MDD and Complicated Grief:

Major Depression: Pervasive sad mood; Loss of interest or pleasure; Pervasive sense of guilt; Rumination about pervasive failures or misdeeds.

Complicated Grief: Sadness related to missing the deceased; Interest in memories of the deceased maintained; longing and yearning for contact; pleasurable reveries; Rumination focused on death or issues related to the deceased; Preoccupation with positive thoughts of the deceased; intense yearning and craving for the person who died; Intrusive images of the person dying; Avoidance of situations and people related to reminders of the loss.

- Differences between PTSD and Complicated Grief:

Posttraumatic Stress Disorder: Triggered by physical threat; Primary emotion is fear; Nightmares are very common; Painful reminders linked to the traumatic event, usually specific to the event.

Complicated Grief: Triggered by loss of a close attachment; Primary emotion is sadness; Nightmares are rare; Painful reminders more pervasive and unexpected; Yearning and longing for the person who died; Pleasurable reveries. 
Adjustment disorders are defined in turn as the onset of emotional or behavioral symptoms that occur within three months of a stressor. The reaction must be disproportionate to the stressor and produce significant impairment in social or occupational functioning. Stressors are normal life experiences (change of address, illness or illness of a family member, work problems, relationship problems, separation, job loss, etc.). The DSM-IV-TR distinguishes various types: with depressed mood, with anxiety, with anxiety and depression; with altered behavior; with emotional and behavioral alteration and nonspecific. Although most tend to subside with the passage of time, some may become chronic.

\subsection{Complicated grief: New definition and controversial issues of DSM}

Currently, the most important social issue with respect to complicated grief involves its status as a pathological condition, as a mental disorder for inclusion in systems such as the DSM. There is a growing debate about whether Complicated Grief should be included in the DSM-V as a disorder.

Recently, Prigerson, Vanderwerker, and Maciejewski (2008) presented a case for changing the terminology from Complicated Grief (CG) to prolonged grief disorder (PGD). They now use the term Prolonged Grief Disorder (PGD) to refer to the syndrome specific to bereavement.

The change in terminology increases clarity in the definition of the disorder.

In the past the term traumatic grief created confusion with posttraumatic stress disorder (PTSD), and pathological grief had pejorative connotations. The concept complicated etymologically refers to "problems of analysis, understanding and explanation" and therefore we have considered it inadequate for its use in the new proposal which characterizes the bereavement specific form of distress. In addition, complicated grief can be confused with complicated bereavement which is the term used in the DSM-IV to refer to symptoms of major depression secondary to bereavement.

The term prolonged best expresses the nature of this disorder. Prolonged does not imply that duration is the only indicator of the pathological grief, it refers to a persistent set of specific symptoms of grief identified in bereaved individuals with significant difficulties in adapting to the loss (Prigerson et al., 2008, pp. 166).

In addition to proposing specific diagnostic criteria, the authors present descriptive features, risk factors, outcomes, and differential diagnoses for prolonged grief disorder. Prigerson et al. (2008) have produced a diagnostic algorithm for Prolonged Grief Disorder (POD), a criteria set that specifies that the reaction has to follow the loss of a significant other.

The proposed Prolonged Grief Disorder Criteria for the Fifth Edition of the Diagnostic and Statistical Manual of Mental Disorders (Prigerson et al., 2008, pp. 171) is:

Criterion A: Bereavement: the bereaved person must experience at least one of the following three symptoms daily or to an intense or disruptive degree: (a) intrusive thoughts related to the deceased, (b) intense pangs of separation distress, or (c) distressingly strong yearnings for that which was lost.

Criterion B: Separation Distress: The bereaved person must have five of the following nine symptoms daily or to an intense or disruptive degree: (a) confusion about one's role in life 
or a diminished sense of self (e.g., feeling that a part of oneself has died); (b) difficulty accepting the loss; (c) avoidance of reminders of the reality of the loss; (d) an inability to trust others since the loss; (e) bitterness or anger related to the loss; (f) difficulty moving on with life (e.g., making new friends, pursuing interests); (g) numbness (absence of emotion) since the loss; (h) feeling that life is unfulfilling, empty, and meaningless since the loss; and (i) feeling stunned, dazed, or shocked by the loss.

Criterion C: Cognitive, Emotional, and Behavioural Symptoms: Duration of at least 6 months from the onset of separation distress.

Criterion D: Duration: and the preceding symptomatic disturbance must cause clinically significant distress or impairment in social, occupational, or other important areas of functioning (e.g., domestic responsibilities), Further requirements stipulate that the disturbance is not due to the physiological effects of a substance or a general medical condition and that the symptoms could not be better accounted for by post-traumatic stress disorder (PTSD), major depression(MDD) and generalized anxiety disorder (GAD).

On the other hand, Rubin et al. (2008) have suggested the inclusion of more features, in the category of complicated grief in the DSM, in order to put the focus on the relationship, and not only on the dysfunction, also taking into account the interpersonal nature of the loss.

Rubin et al. (2008) propose the representation of a wide spectrum of responses within the construct of complicated grief. They are concerned about the exclusion of cases of complications in bereavement, and argue that the category should be relevant enough to include the many forms of difficulties that arise in bereavement. They also raise doubts about the "medicalization" of grief responses and the possibility that a formal diagnosis could hinder the care and support offered by the various cultural expressions of grief and natural healing or complications connected with the loss. While considering the nature of complicated grief and its status in the DSM, it is also important to address the question of subtypes. Prigerson and Jacobs (2001) noted that the concept of complicated grief in the DSM was similar to chronic grief. This left out the other subtypes of different origin (involving absent, delayed, or inhibited grief).

Currently, Prigerson et al. (2008), in their proposed criteria for the inclusion of prolonged grief disorder in the DSM, specify that "the particular symptomatic distress must persist for at least six consecutive months, regardless of when those six months occur in relation to the loss". This includes the subtype of delayed grief distress provided the symptom persists for at least six months.

Authors such as Frances et al. (2010) in relation to some of the current proposals to include complicated grief in the DSM-V, say, "The recently posted draft of DSM5 makes a seemingly small suggestion that would profoundly impact how grief is handled by psychiatry. It would allow the diagnosis of Major Depression even if the person is grieving immediately after the loss of a loved one. Many people now considered to be experiencing a variation of normal grief would instead get a mental disorder label.

Undoubtedly, this would be helpful for some people who would receive much needed treatment earlier than would otherwise be the case. But for many others, an inaccurate and unnecessary psychiatric diagnosis could have many harmful effects. Medicalizing normal grief stigmatizes and reduces the normalcy and dignity of the pain, shortcircuits the 
expected existential processing of the loss, reduces reliance on the many well established cultural rituals for consoling grief, and would subject many people to unnecessary and potentially harmful medication treatment."

Responding to Frances et al. (2010), Pies y Zisook say, “We stand by our previous review of the most pertinent recent data, which informs us that continuing the bereavement exclusion (BE) for the diagnosis of major depression does more harm than good. The BE ignores much of this recent evidence, and we agree with the DSM committee's pithy but astute rationale for discontinuing the $\mathrm{BE}$-that there is no credible evidence that bereavement-related depression is different (in severity, course, morbidity, comorbidity, consequences, or treatment response) from other, non-bereavement-related instances of major depressive episodes.

Notably, the International Classification of Diseases (ICD-10) also omits the BE. While rates of clinically serious depression may be somewhat higher when ICD-10 (vs DSM-IV) criteria are used, we are not aware of any evidence demonstrating an 'epidemic of psychiatric grief' resulting from the use of ICD depression criteria."

Finally, the latest investigations conducted by Prigerson et al. (2008) and Rubin et al. (2008) argue that complicated grief is a distinct clinical entity and that it overlaps little with other diagnostic categories, such as depression.

Clearly, the development of specific diagnostic criteria for Complicated Grief is a current and important debate and direction for future research.

\section{Predictors in complicated grief: A risk factor overview}

There are a variety of ways and moments to express grief over the death of a loved one. Sometimes people do not follow the "normal" grief process. They express it in a way that does not seem adaptive and it significantly interferes in their general functioning, forcing them to look for professional help. These reactions have been called abnormal, complicated, neurotic, morbid, distorted, traumatic or pathological grief.

Studies of risk predictors allow us to identify people who might need support after the loss of a loved one. If it is possible to anticipate who may have difficulties in resolving the grief, it also may act as a prevention and an early intervention (if necessary) to optimize and avoid possible unresolved grief.

The study of risk factors regarding complicated grief allows for the detection and later followup of people with risk of suffering complications in the process. This benefits the entire health network in the short, medium and long term. Early identification of those people who need help to deal with their grief could facilitate early psychological or medical support. The study of risk factors has an important role in the development and testing of theoretical explanations of the impact of grief on health.

Supporting a person with complicated grief risk could reduce the time of the process and prevent future pathologies, depression being one of the most common (Stroebe \& Shut, 2001).

Clinical experience and scientific studies warn of the existence of factors linked to poor results in the adequate resolution of grief. We know that when there is loneliness or intense 
sadness in conjugal bereavement, the risk of physical problems and death increases. Similarly, the death of a child is associated with high morbidity of the surviving parents. Moreover, factors such as sudden or multiple death, low perceived social support or scarce material resources have also been associated with increased risk of health problems (Sanders, 1999).

A risk factor is a lifestyle or personal behavior issue, an environmental situation or an innate or inherited characteristic based on epidemiological evidence. It is associated with health conditions and it is considered important to prevent (Stroebe \& Schut 2001).

From a clinical health perspective, it is necessary to identify risk factors that determine possible complications in the grief process. It is also important to identify those factors that may protect people who are going to experience a grief process. The efficient and effective clinical intervention has always considered important both the recovery and the promotion of the individual's resources and attention to their deficits (Barreto et al., 2008). However, there is little information from which we can draw definite conclusions. There is a lot of work to do in this field in order to obtain indicators related to protective factors.

In this study we show some information regarding risk factors (Barreto et al., 2008). We group them into three categories: situational, personal and interpersonal.

\subsection{Situational factors}

Situational factors make reference to issues that affect the course of grief. This group includes the way in which death has occurred, the duration of the disease, the existence of a concurrent crisis, insufficient material resources and stigmatized deaths.

Sudden unexpected death takes place as a result of a natural or caused catastrophe, an accident, suicide or murder. Within this group difficulty may be aggravated in the case of a multiple loss (for example, several members of a family die in an accident or attack) or in certain circumstances in which there is no certainty of loss due to a disappearance or the inability to recognize the body.

Sudden unexpected death produces a state of shock that greatly reduces the capacity to cope so that full functioning takes time to recover. The survivors of this type of death show more rage and physical symptoms than members of a family who lose a loved one after an illness. Unexpected death leaves the mourners with a sense of loss of control and loss of confidence in the world in which they had previously put their faith. It is usual that this type of death has a child or a son or daughter as the protagonist, a theme which we will discuss more later, and that obviously aggravates the situation.

Sanders (1999) considers suicide a risk factor for illness and death of the survivors but underlines the difficulty of studying it since people do not usually speak of it. Stroebe and Schut (2001) note the lack of empirical evidence supporting greater difficulty in bereavement for suicide. Probably this is due to methodological problems since this type of death favors sentiments of guilt and rumination about previous situations and the outcome, making it harder for the survivor to recover.

Intuitively we know that the death of one's wife in an accident while going to work is not the same as if it happens after several months of illness. The existence of a serious health 
problem can prepare one for the outcome and promotes the proper resolution of grief, especially if one has cared for and is secure in having adequately supported the loved one. On the other hand, if the duration of the disease has been very long (more than 12 months) and has required a lot of care, the recuperation is likely to occur more slowly because of the exhaustion of the survivor and the painful memory of the process.

The existence of concurrent crisis, that is to say, additional stressors during bereavement may cause an overload. It is easy to understand that the simultaneous presence of other problems such as the loss of a job or of financial resources, a change of address, the appearance of a disease or the presence of other sick or disabled family members may require the development of adaptive resources at a time when the mourner may be operating at a disadvantage, a situation which makes him even more vulnerable.

Likewise, scarce material resources complicate the painful existence of the survivor, producing a poor adjustment to the loss. On the other hand, the recovery is strongly associated with the bereaved having a good economic situation (Sanders 1999).

Finally, regarding situational factors, stigmatized death should be mentioned. Abortion, suicide (which has already been mentioned), death caused by AIDS or other socially marked diseases, or the loss of relationships that society rejects entail a more difficult mourning because of social disapproval, the accompanying concealment or exclusion in the planning of care during the illness and of funeral rites (Sanders 1999, Worden 1997).

\subsection{Personal factors}

Personal factors basically refer to the individual features of survivors that influence the process of recovery from loss. Based on available studies, the most important variables are: age and gender of the bereaved, personality, previous health, religion, early loss of parents, previous unresolved grief and emotional reactions of anger, bitterness and intense guilt.

The age and the health of the bereaved are inversely related. Younger age groups present more physical discomfort (headaches or stomach pain) than psychological discomfort as a result of bereavement (Stroebe and Schut 2001; Oltjenbruns 2001 and Balk and Corr 2001).

When age in the marital context has been studied, it has been found that younger spouses have a higher intensity of grief but after two years there is a significant improvement. Being young it is easier to see a better future with new feelings of hope. On the other hand, elderly widows initially show a less intense grief but two years later their health is more fragile and the perception of grief becomes more negative than in the case of younger widows (Sanders 1989,1999).

Regarding the effect of gender on bereavement's outcome there is no agreement in the results of scientific studies. Some conclude that widows suffer more health problems than widowers, although most researchers say the opposite. Others find no significant differences. Sanders (1999) considers that the available body of knowledge supports the conclusion that men suffer more severe health consequences after the loss of a partner than women, although conclusive reasons have not yet been found regarding the causes of this difference.

It is plausible that people with well-adjusted personalities and feelings of control over their lives manage better the impact of stressful life events. On the contrary, those with poor 
adjustment, difficulty expressing emotions, inability to handle stress, little sense of control and low frustration tolerance are more likely to have difficulties recovering from a relevant loss.

In the same sense, people with fragile mental and physical health previous to a loss worsen in a stress situation. It is known that grief exacerbates congestive heart failure and essential hypertension. Moreover, Bunch (1972) investigated the phenomenon of suicide in mourners and found that $60 \%$ of them were under psychiatric treatment before the bereavement. Obviously it is easier to detect and diagnose premorbid physical problems than psychiatric problems because people find it is easier to talk about them, but it is essential to take them into account in the light of experience. It has also been observed that people who use health services prior to the loss of a loved one are more susceptible to complications in the grieving process.

On the other hand, it is believed that religion can influence bereavement through two mechanisms: as social support because of the integration into a group and as a belief system that helps in the search for meaning in death. However, the results of the studies are contradictory and may be due to methodological issues or different modes of experiencing religious phenomena (Stroebe and Shut 2001).

Also, the early loss of parents and previous unresolved bereavements impede recovery, since the new death can make them emerge to an extent that has not been reached before (Neimeyer et al, 2010) or the difficulties created by them have not been resolved.

Finally, experimenting and expressing emotional reactions of anger, bitterness or intense guilt predicts long-term complications in the adequate resolution of bereavement except in those mourners who have maintained very contentious relationships with the deceased (Bonanno, 2001b).

\subsection{Interpersonal factors}

Interpersonal factors refer to relevant aspects of the relationship with the deceased and the social network. We emphasize within this category kinship, ambivalent or dependent relationship, lack of social support and the painful memory.

Kinship is an important variable in predicting the risk of complications in mourning. Parents are not prepared to survive a child. When this happens, they say that they feel like a part of themselves has died and the "why" becomes an obsessive rumination. The feeling of loss of control over their lives and the world and of insecurity is very strong. Somatic reactions, the degree of depression, guilt and anger are higher than those experienced in the loss of a spouse or elderly parent. It has also been observed that mothers have higher levels of guilt, anger and isolation than fathers and the support they experienced in the past with their partner is often lost and they find it very hard to show their feelings. The dissolution of marriage, divorce or separation is frequent, estimated to be between 50 and $90 \%$ of cases (Rando 1983). This type of loss can take several years for resolution and, sometimes, family structure may be undermined in such a way that stability can never be completely recovered as a result of "survivor guilt" (feeling guilty for being alive).

Other difficult situations are the loss of a sibling in adolescence, of the father or mother at an early age and of the spouse (some already mentioned). 
Conflicting or ambivalent relationships with the deceased may cause difficulties in the subsequent resolution of grief. The fact of having oscillated between love and hate make more likely the emergence of self-reproaches and self-deprecation which may hamper the recovery.

When the deceased was practically the only source of gratification, problem solving and considering necessary to live and be happy, outliving the deceased may create very high levels of anxiety or hopelessness. These are clear predictors of difficulty in the resolution of bereavement.

The various authors who have worked in this field generally agree about the disturbing role of the lack of social support. A small family with low cohesion and inability to help its members usually will present problems. On the contrary, having family and friends who listen empathetically, without stifling tears or expressions of frustration, has a positive effect on health and will avoid an important risk factor. One example is the added difficulty that may occur by not doing alternative activities and the presence of small children at home, phenomena explained by the social isolation that both situations produce and the consequent decline of social support.

We must not forget that the "painful memory due to late diagnosis, poor control of symptoms or inadequate relationships with healthcare staff are factors that also hinder the resolution of bereavement.

\subsection{Situations for children and adolescents}

Although predictive factors discussed are applicable to all age groups, we also consider in this study some specific high-risk situations for children and adolescents.

The first is an unstable environment with a person responsible for alternate care. As far as possible this situation should be avoided and efforts must be made to ensure continuity of care when parents are not in condition to provide it. The second refers to the dependence on the surviving parents and their reaction to the loss (it should not be forgotten that for children a very important kind of learning is the model that adults provide for them). The third is the existence of remarriage and the presence of a negative relationship with the new parent. The fourth is the loss of the mother for girls younger than 11 and the father in adolescent boys. And fifth is the lack of consistency in disciplining the child or adolescent.

\section{Predictors in complicated grief: Some ideas about protective factors}

We also briefly analyze protective factors grouped into three categories (based on review of scientific literature, our preliminary research results and our clinical experience): coping strategies, protectors deduced from the study of risk factors and, finally, other factors identified from clinical experience.

\subsection{Coping strategies}

Coping strategies are what we call the different ways or strategies that people use consciously, and very often unconsciously, to reduce, manage and survive the physical, mental and emotional symptoms naturally encountered in bereavement.

In the theory of stress, bereavement is considered a stressor which requires coping directed at the problem and coping directed at emotions in different moments. The first type of 
coping would be more appropriate in situations that can be modified and the second would be more useful in irreversible situations. Therefore, in the grieving process, these two components have different roles at different points in time, from the anticipation of the loss to the resolution of grief.

Some of the few findings in this field are those of Benight, Flores \& Tashiro (2001) who found in a sample of widows with a mean age of 54 that dealing effectively with bereavement significantly predicted psychological and spiritual well-being and perception of health 6 months or more after the death of the spouse. These data refer to general mechanisms, not specific to the process, and at present are not clinically applicable.

On the other hand, spirituality is a well-documented resource for coping. Religious and spiritual beliefs and related behaviors appear to facilitate a positive adjustment to the loss of a loved one.

As it can be seen, there is very little data from which we can draw definitive conclusions. It is quite possible that the theme of bereavement has special difficulties preventing it from being investigated in the same manner as other stressors, and probably the instruments designed to assess coping in other areas are inadequate in this area, as mentioned.

\subsection{Protectors deduced from the study of risk factors}

Obviously, many risk factors can be considered in reverse as protectors. Consider for instance the case of family support, occupation or the absence of economic difficulties. In the same way, these might act as protectors: feelings of usefulness, the absence of prior pathology, knowledge of the prognosis of the illness adjusted to reality, etcetera. (See Risk Factors).

However, we cannot simply assume that the inverse of a risk factor necessarily implies a protector, so we need to empirically assess its specific role in future studies of predictive indicators.

\subsection{Other factors identified from clinical experience}

Finally, there is another group of variables found in clinical practice that have proven their efficacy as protectors in other areas in the field of health and which would be very interesting to consider in the present one. We refer to fluency in communication, perceived self-efficacy, feelings of usefulness in the care of the sick, the ability for planning and problem solving, mental flexibility, self-care and the ability to find meaning in the experience.

\section{Supporting families to deal with grief: Some ideas about intervention}

Bereavement is an adaptive process that restores the balance broken after the loss and can positively contribute to personal growth (Davis \& Asliturk, 2011). Most people adjust without professional help, but a minority are at risk of suffering lasting health consequences.

There is no final end of bereavement but we can deduce that it is completed when the intense pain gives way to quiet and affectionate remembrance of the past. The duration of 
the process is usually one to two years but this will depend, like its intensity, on the importance of the deceased, on socio-cultural factors and on certain circumstances which are predictors of greater difficulty in resolving bereavement (Barreto \& Soler, 2007; Barreto et al. 2000).

Following Gamo \& Pazos (2009) with regard to mourning it is important to consider that:

- There is an interrelation between personal history, psychopathology and bereavement.

- Evolution towards a pathological bereavement occurs only in a minority of cases.

- Bereavements, whether or not ending in pathology, are important milestones in the biographical history because of their character of permanent loss and because they mark the resumption of the biographical line after the loss.

- The effects of bereavement can be very long, variable in time, reactivated by other bereavements, other losses, and by multiple relationships or biographical circumstances. Those occurring at one moment may affect others occurring later.

- Bereavements in infancy may condition later biographical development and configure aspects of the personality.

- Bereavement marks the succession of the generations, some have transgenerational effects.

- Bereavement is implicated in triggering or it is related to a very diverse set of clinical syndromes.

- The understanding of certain symptoms, behaviors and life situations can be related to bereavement: this repositions for us the meaning of certain symptoms or behaviors that can have identifying, imitative, repetitive or compulsive shades of meaning.

- The impact of grief in life is always a process, the important thing is not only the event, but the situation and its evolution. Because of this, relations after bereavement are decisive: support, substitute relationships, later losses.

Psychological support in caring for bereaved people includes a wide spectrum of activities (Raphael et al., 2001/2001b; Barreto \& Soler, 2003; Barreto, Yi \& Martínez, 2003; Soler \& Barreto, 2003). Bereavement is a normal phenomenon and routine psychotherapeutic or pharmacological interventions are not justified (Raphael et al., 2001b). Grief interventions are indicated only in specific circumstances and connected to different moments of the process. Bereavement interventions can be divided into two phases: before and after the death of the loved one (Barreto \& Soler, 2007).

From a health perspective we can carry out preventive actions aimed at facilitating the development of grief and minimizing the risk of complicated grief, such as (Barreto \& Soler, 2007):

- Identify the needs and preoccupations of the loved ones

- Provide information that facilitates coping with the situations of terminal illness and death

- Help the family accept the death of the patient

- Identify the risk factors for complicated grief

- Identify the protective factors of adaptive grief

Preventive interventions of a universal nature, namely those aimed at the general population of mourners, show inconsistent and disappointing results, except for intervention in children which must follow an age-specific approach. Selective preventive 
interventions designed for mourners showing greater vulnerability have modest results but very good results for certain groups such as bereaved parents with perinatal or neonatal losses, elderly with risk of depression and widows at risk and needing social support. Preventive interventions programmed for people with an incipient pathology or with high levels of discomfort at the beginning of bereavement, have proven very useful.

In interventions after the death of the patient certain aspects should be considered important (Barreto \& Soler, 2007):

- People are unique in their manner of living and expressing their pain at the death of a loved one.

- $\quad$ Bereavement is not an illness: Most people have a 'normal' bereavement and adapt to the loss and its consequences.

- The processes of both normal and complicated bereavement are slow.

- Intervention in bereavement re-orders relations, which does not mean helping to forget the loved one.

- In the course of the process of bereavement a wide range of emotions may be present. Some only negative, such as sadness, anger, impotence, guilt, anxiety, and fear, but also some positive, such as joy, pride, satisfaction, gratitude, love, and others.

Following Rando (Rando, 1993; Solomon \& Rando, 2007) the general objectives of the intervention in bereavement would be:

- Develop relationships which connect the bereaved with the deceased in a new form given the deceased's absence. Here the focus is on the loved one who has been lost.

- Personal adaptation to the loss. Here the focus is on the bereaved, implying their revision of their worldview and on their own identity which has been impacted through the loss (Calderwood, 2011).

- Learning to adapt to the new world without the deceased. The focus is on the external world and how the bereaved lives in it.

Therapeutic interventions aimed at helping people showing complications in the mourning, and maintenance interventions, which seek to rehabilitate mourners increasing their quality of life and helping in any residual disorder, have been shown to be largely effective (Altmaier, 2011; Drenth et al. 2010; Molero \& Perez, 2009; Lacasta \& Soler, 2006; Lacasta \& Garcia, 2011, Lopez et al. 2010; Portillo et al, 2002; SECPAL, 2011).

The use of drugs for the treatment of complicated grief should be approached carefully for two main reasons: first, because empirical research is inconclusive about the effects of drugs on the intensity of grief; and second, because it could create counterproductive addictions (Barreto \& Soler, 2007; Raphael et al., 2001/2001b, Worden, 1991/1997; Lacasta \& Sastre, 2000).

\section{Conclusion}

In this chapter, firstly we have tried to present an overview of history and current status of some nuclear components of grief. Recently, researchers are working on the clarification of the concept in relation to other phenomena with similar clinical features, the underlying processes, its different manifestations and its evolution (normal and pathological grief). Current studies also consider interpersonal aspects, including social risk factors, the effectiveness of the intervention and the consequences in grief of social networks. 
The loss of a loved one normally has different emotional effects on survivors in function not only of their biography but also of the circumstances. The intensity and duration of the emotional impact will depend greatly on the importance of the loss for the survivor and the unexpectedness of the loss. The clinical presentation of bereavement responds to individual, family, environmental, and cultural variables, although there are common tasks that an individual likely goes through to successfully navigate the grieving. It is very important to know the normal manifestations of bereavement and grieving and to be cautious in their interpretation because otherwise we may make the mistake of considering as pathological, some completely natural and adaptive manifestations of the process.

Sometimes, bereavement does not follow its normal course and there are reactions that clearly interfere with the overall functioning of the person to the point of requiring specialized help. These reactions or states constitute what it has been conventionally called abnormal, chronic, pathological, traumatic, complicated bereavement or grief. The term complicated (or traumatic) grief describes grief that appears to deviate from the norm in duration and symptom intensity. Lately, the concept of prolonged grief disorder is being used. Currently, the focus on complicated grief is not intended to imply that this disorder is the only, because other psychiatric disorders, such as major depression disorder, generalized anxiety disorder, adjustment disorder and posttraumatic stress disorder could be possible as well. So a good and fine differential diagnosis will be of major importance.

The second part of the chapter highlights that we should pay particular attention to possible signs of grief that are not following an adequate course. We show in this work some information regarding risk factors. We group them into three categories: situational, personal and interpersonal. We present as well some information on protective factors that could help people to deal with pain. We briefly comment about protective factors grouped in three categories: coping strategies, protectors deduced from the study of risk factors and, finally, other factors identified from clinical experience.

It is especially important consider the predictors of pathological mourning in order to identify people who are most likely to need support after the loss of a loved one and thus try to prevent a possible complicated grief. However, in situations of pathological mourning, one should accurately assess the specific problem that prevents people from functioning effectively in their daily life, as well as address the aspects related to the loss. The study of risk factors regarding complicated grief allows the detection and later following up of people with risk to suffer complications in the process. This benefits in short, medium and long term to the entire health network. Early identification could make easier an early psychological or medical support, reduce the time process and prevent future pathologies.

Finally, we insist in the fact that routine psychotherapeutic or pharmacological interventions are not justified. Grief interventions are indicated only in specific circumstances. These interventions may be preventive, therapeutic or follow-up interventions, universal or guided to the general population, referred to groups of "high risk" or indicated in the case of bereaved people who displayed continuous and very high levels of symptoms related to loss. It is also important to identify and to treat grief pathologies as early as possible. Finally, follow-up interventions try to increase quality of life and to help the bereaved people to live as best as possible with their problem and decreasing their morbidity and disability. 


\section{References}

Altet, J. \& Boatas, F. (2000) Reacciones de duelo. Informaciones Psiquiátricas, No.159, pp 17-29.

American Psychiatric Association (APA) (2003) DSM-IV-TR. Manual diagnóstico y estadístico de los trastornos mentales. Barcelona: Masson.

Amurrio L, \& Limonero JT. (2007) El concepto de duelo en estudiantes universitarios. Med Paliat, Vol. 14, No. 1, pp. 14-9.

Altmaier, EM. (2011) Best Practices in Counseling Grief and Loss: Finding Benefit from Trauma. Journal of Mental Health Counseling, Vol. 33, No. 1; pp. 33-45.

Balk DE y Corr CA (2001) Bereavement during adolescence: A review of research. En: MS Stroebe RO Hansson W Stroebe y H Schut (Ed.) Handbook of bereavement research: Consequences, coping, and care (pp. 199-218). Washington: American Psychological Association.

Barreto MP; Molero M \& Pérez MA (2000) Evaluación e intervención psicológica en familias de enfermos oncológicos. In: F Gil (Ed.) Manual de psico-oncología. Madrid, Nova Sidonia.

Barreto, P. \& Soler, C. (2003). Psicología y Fin de Vida. Revista de Psicooncologia, Vol. 0, No 1, pp. 135-146.

Barreto, MP; Yi, Patricia \& Martínez, E. (2003). Apoyo psicológico en la fase final de la vida. Revista de Psicología UniversitasTarraconensis, Vol. 25, No.1-2 , pp. 193-209.

Barreto P \& Soler MC. (2007) Muerte y Duelo. Madrid: Síntesis.

Barreto, P., Yi, P. \& Soler, C. (2008) Predictores de duelo complicado. Revista de Psicooncologia, Vol. 5, No. 2-3, pp.383-400.

Bayés, R. (2001). Psicología del sufrimiento y de la muerte. Martinez Roca: Barcelona.

Bayés, R. (2006). Afrontando la vida, esperando la muerte. Madrid: Alianza

Benight, C, Flores, J. \& Tashiro, T. (2001) Bereavement coping self-efficacy in cancer widows. Death studies, Vol. 25, No 2, pp. 97-125.

Bonanno GA, \& Kaltman S. (1999) Toward an integrative perspective on bereavement. Psychol Bull , Vol. 125, No. 6, pp. 760-77.

Bonanno GA, \& Kaltman S. (2001) The variety of grief experience. Clin Psychol Rev; Vol. 21, No. 5, pp. 705-734.

Bonanno GA (2001b) Grief and emotion: A social-funtional perspective. En: MS Stroebe RO Hansson W Stroebe y H Schut (Ed.) Handbook of bereavement research: Consequences, coping, and care (pp. 493-515). Washington: American Psychological Association.

Bowlby J (1993) El vínculo afectivo. La separación afectiva. La pérdida afectiva. Barcelona: Paidós. Psicología Profunda.

Calderwood, KA. (2011) Adapting the Transtheoretical Model of Change to the Bereavement Process. Social Work; Vol. 56, No. 2, pp. 107-118.

Chiu YW, Huang CT, Yin SM, Huang YC, Chien CH, Chuang HY. (2010) Determinants of complicated grief in caregivers who cared for terminal cancer patients. Support Care Cancer, Vol. 18, pp. 1321-1327.

Corr, CA, \& Coolican, MB, (2010) Understanding bereavement, grief, and mourning: implications for donation and transplant professionals. Progress in Transplantation; Vol. 20, No. 2; pp. 169-177.

Cunill, M., Clavero, P., Gras, M. \& Planes, M. (2010) Procesos de pérdida: como prevenir futuras dificultades. Cuadernos de medicina psicosomática y psiquiatría de enlace, No 93 / 94, pp. 45-48. 
Davis, CG. \& Asliturk, E (2011) Toward a Positive Psychology of Coping With Anticipated Events. Canadian Psychology, Vol. 52, No. 2; pp. 101-110.

Drenth, C., Herbst, A.G. \& Strydom, H., (2010) A complicated grief intervention model. Health SA Gesondheid, Vol. 15, No 1, pp. 1-8. Available from http:/ / www.hsag.co.za. Art. \#415, 8 pages. DOI: 10.4102/hsag.v15i1.415

Forstmeier S, Maercker A. (2007) Comparison of two diagnostic systems for Complicated Grief. J Affective Disorders, Vol. 99, pp. 203-211.

Frances, A., Pies, R. \& Zisook, S. (May 2010) DSM5 and the Medicalization of Grief: Two Perspectives. Psychiatric times, 13 May 2010, No 10168, pp. 46-47. Available from http://www.psychiatrictimes.com/dsm-5/content/article/10168/1568760.

Gamo, E. \& Pazos, P. (2009) El duelo y las etapas de la vida. Revista de la asociación española de neuropsiquiatría, Vol. 29, No 104, pp. 455-469.

Gamo, E., De alamo, Hernan Gomez (2000) Problemática clínica del duelo en la asistencia en Salud Mental, Psiquiatría Pública, 12 (3), 209

García-García JA, Landa V, Prigerson H, Echeverria M, Grandes G, Mauriz A, \& Andollo I. (2002) Adaptación al español del Inventario de Duelo Complicado (IDC). Medicina Paliativa, Vol. 9, No. 2, pp. 10-1.

Gil-Juliá, B., Bellver, A. \& Ballester, R. (2008) Duelo: evaluación, diagnóstico y tratamiento. Revista de Psicooncologia, Vol. 5, No. 2-3, pp. 103-116.

Grimberg, L. (1980) Identidad y cambio.Buenos Aires, Paidos.

Hansson, R., \& Stroebe, M. (2007). Bereavement in late life. Washington DC: American Psychological Association

Hebert RS, Schulz R, Copeland VC, \& Arnold RM. (2009) Preparing family caregivers for death and bereavement. Insights from caregivers of terminally ill patients. J Pain Symptom Manage; Vol. 37, No. 1, pp. 3-12.

Horowitz MJ, Siegel B, Holen A, Bonanno GA, Milbrath C, Stinson CH. (1998) Diagnostic criteria for complicated grief disorder. Am J Psychiatry, Vol. 155, No. 9, pp. 13051306.

Howarth, A. (2011) Concepts and Controversies in Grief and Loss. Journal of Mental Health Counseling; Vol. 33, No 1; pp. 4-10.

Jacobs SC. (1999) Traumatic grief: Diagnosis, treatment and prevention. Philadelphia: Brunner/Mazel,.

Kristjanson LJ, Cousins K, Smith J, \& Lewin G. (2005) Evaluation of the Bereavement Risk Index (BRI): A community hospice care protocol. Int J Palliat Nurs; Vol 11, No. 12, 610-618.

Kissane D, Bloch S \& McKenzie D. (1997) Family coping and bereavement outcome. Palliative Medicine, Vol. 11, pp. 191-201.

Kubler-Ross, E. (1969/1975/2000). Sobre la muerte y los moribundos. Barcelona: Grigalbo Mondadori.

Lacasta MA \& Soler MC. (2004) El duelo: prevención y tratamiento del duelo patológico. Cuidados después de la muerte. In: Manual SEOM de Cuidados Continuos. Madrid: Dispublic.

Lacasta, M., \& Sastre, P. (2000). El manejo del duelo. In M. Die Trill, \& E. López Imedio, Aspectos psicológicos en cuidados paliativos. La comunicación con el enfermo y la familia Madrid: Ades Editores.

Lacasta MA \& Soler MC. (2006) Instrumentos de evaluación en duelo. In: González Barón M, Ordóñez Gállego A. \& Lacasta Reverte MA (Eds.) Valoración Clínica en el paciente con Cáncer. Madrid: Editorial Médica Panamericana. 
Lacasta Reverte MA \& García Rodríguez ED (July 2011) El duelo en cuidados paliativos. SECPAL. Guías Medicas. Available from: http://www.secpal.com

Limonero JT. (1996) El fenómeno de la muerte en la investigación de las emociones. Rev Psicol Gen Aplic; Vol. 49: pp. 249-265.

Limonero, J, Lacaste, M., García, J.A., Maté, J. \& Prigerson, HG. (2009) Adaptación al castellano del inventario de duelo complicado. Medicina paliativa, Vol. 16: N.o 5; pp. 291-297.

López de Ayala García; C., Galea Martín; T \& Campos Méndez, R. (2010) Guía Clínica. Seguimiento del duelo en Cuidados Paliativos. Observatorio Regional de Cuidados Paliativos de Extremadura.

Maciejewski PK, Zhang B, Block SD, \& Prigerson HG. (2007) An empirical examination of the stage theory of grief. JAMA, Vol. 297, No. 7, pp. 716-723.

Maddocks I (2003) Grief and bereavement. Med J Aust, Vol. 179 , No. suppl 6, pp. s6-s7.

Maercker A, Fortmeieer S, Enzler A, \& Ehlert U. (2005) Complicated grief as a stress response syndrome: results from the Zurich older age study. Paper presented at the 7 th International conference on grief and bereavement in contemporary society, London,.

McChrystal J. (2008) The psychological impact of bereavement on insecurely attached adults in a primary care setting. Couns Psychother Res ; Vol. 8, No. 4, 231-238.

Meuser T \& Marwit S (2001) A comprehensive, stage-sensitive model of grief in dementia caregiving. The Gerontologist, 41 (5), 658

Molero, M. \& Pérez, M. (2009) El duelo, la familia, el trauma y el EMDR: Análisis de un caso clínico. Mosaico-Revista de la Federación española de asociaciones de terapia familiar, Vol.42, pp. 28-35.

Moules, N. J., Simonson, K., Fleiser, A. R., Prins, M., \& Glasgow, B. (2007). The Soul of Sorrow Work: Grief and Therapeutic Interventions With Families. J Fam Nurs, Vol. 13, No. 1, pp. 117-141

Neimeyer RA. (2002) Aprender de la pérdida.Barcelona: Paidós.

Neimeyer, R., Burke, L., Mackay, M., Van Dyke Stringer, J. (2010) Grief Therapy and the Reconstruction of Meaning: From Principles to Practice. Journal of Contemporany Psychothery, Vol. 40, pp. 73-83.

Olmeda, MS, García, A. \& Basurte, I. (2002) Rasgos de personalidad en duelo complicado. Psiquiatría.com, Vol. 5, No 5, 1-12.

Oltjenbruns KA (2001). Developmental Context of childhood: Grief and regrief phenomena. En: MS Stroebe, RO Hansson, W Stroebe y H Schut (Ed.) Handbook of bereavement research: Consequences, coping, and care (pp. 169-197). Washington: American Psychological Association.

Organización Mundial de la Salud, CIE. (1992) Clasificación internacional de las enfermedades: Trastornos mentales y del comportamiento. $10^{\mathrm{a}} \mathrm{ed}$. Zaragoza: Meditor.

Parkes CM. (1970) Seeking and finding a lost object: Evidence of recent studies of the reaction to bereavement. Social science \& medicine;, Vol. 4, No. 2, pp. 187-201.

Parkes CM. (1988) Research: bereavement. Omega, Vol. 18, No. 4, pp. 365-377.

Parkes CM. (1990) Risk Factors In Bereavement: Implications for the prevention and treatment of pathologic grief. Psychiatr Ann; Vol. 20, No. 6, pp. 308-313.

Parkes CM \& Weiss RS (1983) Recovery from bereavement. New York: Basic Books.

Payás A. (2007) Intervención grupal en duelo. In: Camps C, Sánchez PT, (eds). Duelo en Oncología. Madrid: Sociedad Española de Oncología Médica.

Payás, A. (2008) Funciones psicológicas y tratamiento de las rumiaciones obsesivas en el duelo. Revista de la asociación española de neuropsiquiatría, Vol. 28, No 102, pp. 307-323. 
Portillo, M., Martín, M.J. \& Alberto, M. (2002) Adherencia al tratamiento del duelo patológico. Cuadernos de medicina psicosomática y psiquiatría de enlace, No 62 / 63, pp. 13-18.

Prigerson, H.G.; Shear, M.K.; Jacobs, S.C.; Reynolds III, C.F.; Maciejewski, P.K.; Davidson, J.R.T.; Rosenheck, R.A.; Pilkonis, P.A.; Wortman, C.B.; Williams, J.B.W.; Widiger, T.A.; Frank, E.; Kupfer, D.J. y Zisook, S. (1999). Consensus criteria for traumatic grief. A preliminary empirical test. British Journal of Psychiatry, Vol. 174, pp. 67-73.

Prigerson, H.G. \& Jacobs, S.C. (2001). Traumatic grief as a distinct disorder: A rationale, consensus criteria, and a preliminary empirical test. In: M.S. Stroebe, R.O. Hansson, W. Stroebe \& H. Schut (Eds.), Handbook of bereavement research: Consequences, coping, and care (pp. 613-645). Washington: American Psychological Association.

Prigerson, H. G., \& Jacobs, S. (2001). Traumatic grief as a distinct disorder: A rationale, consensus criteria, and a preliminary empirical test. In M.S. Stroebe, R.O. Hansson, W. Stroebe, \& H. Schut (Eds.), Handbook of bereavement research: Consequences, coping, and caring Washington, DC: American Psychological Association.

Prigerson, H. G., Vanderwerker, L. C, \& Maciejewski, P. K. (2008). A case for inclusion of prolonged grief disorder in DSM-V. In M.S. Stroebe, R.O. Hansson, H. Schut, \& W. Stroebe (Eds.), Handbook of bereavement research and practice: Advances in theory and intervention Washington, DC: American Psychological Association.

Rando TA (1983) An investigation of grief adaptation in parents whose children have died from cancer. Journal of Pediatric Psychology, Vol. 8, pp. 3-20.

Rando, T. (1993) Treatment of complicated mourning. Champaign, IL: Research Press

Raphael B, Middleton W, Martinek N, Misso V. (2001) Counselling and therapy of the bereaved. In: M.S. Stroebe, R.O. Hansson, W. Stroebe y H. Schut, eds. Handbook of bereavement research: Consequences, coping, and care. Washington: American Psychological Association.

Raphael, Minkov, and Dobson (2001b). Psychotherapeutic and pharmacological intervention for bereaved persons. In: M.S. Stroebe, R.O. Hansson, W. Stroebe y H. Schut, eds. Handbook of bereavement research: Consequences, coping, and care. Washington: American Psychological Association.

Rubin, S., Malkinson, R., \& Witztum, E. (2008). Clinical aspects of a DSM Complicated Grief Diagnosis: Challenges, dilemmas, and opportunities. In M. S. Stroebe, R. O. Hansson, H. Schut \& W. Stroebe (Eds) Handbook of Bereavement Research and Practice: Advances in Theory and Intervention (pp 187 - 206). Washington, DC: American Psychological Association Press.

Sanders CM (1999) Risk factors in bereavement outcome. In: MS Stroebe, W Stroebe y RO Hansson (Ed.) Handbook of bereavement: Theory, research, and intervention (pp. 255267). Cambridge: Cambridge University Press.

Secpal (2002) Guía de cuidados paliativos. Madrid: Secpal.

Shear, M.K., Frank, E., Houck, P.R., \& Reynolds, CF. (2005). Treatment of complicated grief: A randomized controlled trial. JAMA, Vol. 293, pp. 2601-2608.

Shear, MK. \& Mulhare, E. (2008) Complicated Grief. Psychiatric annals, Vol. 38, No. 10, pp. 662-670.

Shimshon, S., Malkinson, R. \& Witztum, E. (2008). Clinical aspects of a DSM complicated grief diagnosis: challenges, dilemmas and opportunities. In M.S. Stroebe, R.O. Hansson, H. Schut, \& W. Stroebe (Eds.), Handbook of bereavement research and practice: Advances in theory and intervention Washington, DC: American Psychological Association. 
Sociedad Española de Cuidados Paliativos (SECPAL). (July 2011) Guía de duelo para familiares. Sociedad Española de Cuidados Paliativos. Available from http://www.iconcologia.net/catala/hospitalet/imatges /model_guiadol.pdf.

Soler, M. C. \& Jorda, E. (1996). El duelo: manejo y prevención de complicaciones. Medicina Paliativa, Vol 3/2,pp. 66-75.

Soler, C. \& Barreto, MP. (2003). Intervención Psicológica en el duelo. Revista de Psicología UniversitasTarraconensis, Vol. 25, No. 1-2, pp. 218-233.

Solomon, R. \& Rando, T. (2007) Utilization of EMDR in the Treatment of Grief and Mourning. Journal of EMDR Practice and Research, Vol.1, No 2, pp. 109-117.

Stroebe W \& Schut H (2001) Risks factors in bereavement outcome: a methodological and empirical review. In: Stroebe $\mathrm{M}$ et al. (Ed.) Handbook of bereavement research: consequences, coping and care. Washington: American Psychological Association,

Stroebe, M.S., Hansson, R.O., Stroebe, W. \& Schut, H. (eds.) (2001b) Handbook of bereavement research: Consequences, coping, and care. Washington: American Psychological Association.

Stroebe, M.S., Schut, H \& Stroebe, W. (2007) Health outcomes of bereavement. The Lancet, Vol. 370, No. 9603, pp. 1960-1973.

Stroebe, M.S., Hansson, R.O., Schut, H.A.W. \& Stroebe, W. (Eds.) (2008) Handbook of bereavement research and practice: Advances in Theory and Intervention. Washington: APA.

Stroebe, M.S., Hansson, R.O., Stroebe, W. \& Schut, H. (2008b) Bereavement research: contemporary perspectives. In M.S. Stroebe, R.O. Hansson, H. Schut, \& W. Stroebe (Eds.), Handbook of bereavement research and practice: Advances in theory and intervention Washington, DC: American Psychological Association.

Stroebe, M.S., Hansson, R.O., Stroebe, W. \& Schut, H. (2008c) Bereavement research: 21 st century prospects. In M.S. Stroebe, R.O. Hansson, H. Schut, \& W. Stroebe (Eds.), Handbook of bereavement research and practice: Advances in theory and intervention Washington, DC: American Psychological Association.

Tomarken A, Holland J, Schachter S,Vanderwerker L, Zuckerman E, Nelson C et al. (2008) Factors of complicated grief predeath in caregivers of cancer patients. Psychooncology, Vol. 17, pp. 105-111

Walter (2000) On Bereavement: The culture of grief. Palliative Medicine, Vol. 14, No 1, pp 355

Worden JW. (1991/1997) El tratamiento del duelo. Barcelona: Paidós,.

Wortmann JH, \& Park CL. (2008) Religion and spirituality in adjustment following bereavement: an integrative review. Death Stud; Vol. 32, No. 8, pp. 703-736.

Wortman CB; Silver RC; Kessler RC (1999) The meaning of loss and adjustment to bereavement. En: MS Stroebe, W Stroebe y RO Hansson (Ed.) Handbook of bereavement: Theory, research, and intervention. Cambridge: Cambridge University Press.

Yi, P., Barreto, P., Soler, C., Fombuena, M., Espinar, V., Pascual, L., Navarro, R., González, R., Bernabeu, J. \& Suárez, J. (2006) Grief support provided to caregivers of palliative care patients in Spain. Palliative Medicine, Vol. 20, pp. 521-531.

Zhang B, Areej BS, \& Prigerson H. (2006) Update on bereavement research: evidence-based guidelines for the diagnosis and treatment of complicated bereavement. J Palliat Care; Vol. 9, No. 5, pp. 1188-1203.

Zivin N. Christakis A. (2007) The emotional tool of spousal morbidity and mortality. Am J Geriatr Psychiatry; Vol. 15: 772-779. 


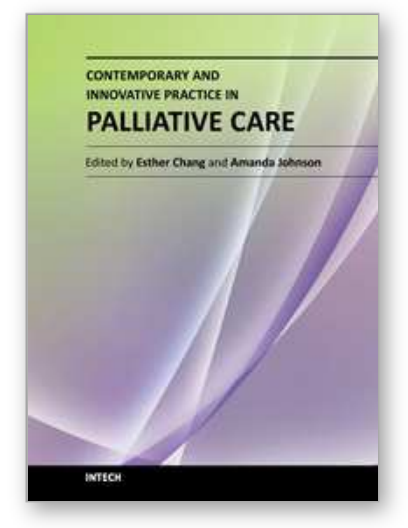

\author{
Contemporary and Innovative Practice in Palliative Care \\ Edited by Prof. Esther Chang
}

ISBN 978-953-307-986-8

Hard cover, 302 pages

Publisher InTech

Published online 10, February, 2012

Published in print edition February, 2012

This book is designed to provide a comprehensive insight unto the key and most prevalent contemporary issues associated with palliation. The reader will find viewpoints that are challenging and sometimes discerning, but at the same time motivating and thought-provoking in the care of persons requiring palliation. This book is divided into three sections. Section 1 examines contemporary practice; Section 2 looks at the challenges in practice; Section 3 discusses models of care. This book is an excellent resource for students, practising clinicians and academics. By reading the book, reflecting on the issues, challenges and opportunities ahead, we hope it will create within the reader a passion to take on, explore and further develop their palliative care practice.

\title{
How to reference
}

In order to correctly reference this scholarly work, feel free to copy and paste the following:

Pilar Barreto-Martín, Marián Pérez-Marín and Patricia Yi (2012). Predictors in Complicated Grief: Supporting Families in Palliative Care Dealing with Grief, Contemporary and Innovative Practice in Palliative Care, Prof. Esther Chang (Ed.), ISBN: 978-953-307-986-8, InTech, Available from:

http://www.intechopen.com/books/contemporary-and-innovative-practice-in-palliative-care/predictors-incomplicated-grief-supporting-families-in-palliative-care-dealing-with-grief

\section{INTECH}

open science | open minds

\author{
InTech Europe \\ University Campus STeP Ri \\ Slavka Krautzeka 83/A \\ 51000 Rijeka, Croatia \\ Phone: +385 (51) 770447 \\ Fax: +385 (51) 686166 \\ www.intechopen.com
}

\author{
InTech China \\ Unit 405, Office Block, Hotel Equatorial Shanghai \\ No.65, Yan An Road (West), Shanghai, 200040, China \\ 中国上海市延安西路65号上海国际贵都大饭店办公楼 405 单元 \\ Phone: +86-21-62489820 \\ Fax: +86-21-62489821
}


(C) 2012 The Author(s). Licensee IntechOpen. This is an open access article distributed under the terms of the Creative Commons Attribution 3.0 License, which permits unrestricted use, distribution, and reproduction in any medium, provided the original work is properly cited. 